\title{
Unsustained Response to Benralizumab in Eosinophilic Asthma After 3 Years of Therapy With Mepolizumab
}

Kurosawa $\mathrm{M}^{1}$, Shimizu $\mathrm{Y}^{2}$, Sutoh $\mathrm{Y}^{3}$, Sutoh $\mathrm{E}^{1,3}$

${ }^{1}$ Department of Allergy and Respiratory Medicine, Sutoh Hospital, Annaka, Gunma, Japan

${ }^{2}$ Division of Respiratory Medicine, Kaminakai Family Clinic, Takasaki, Gunma, Japan

${ }^{3}$ Department of Surgery, Sutoh Hospital, Annaka, Gunma, Japan

J Investig Allergol Clin Immunol 2021; Vol. 31(4): 353-355 doi: 10.18176/jiaci.0652

Key words: Anti-interleukin 5 therapy. Asthma Control Test. Blood eosinophil count. Eosinophilic asthma. FEV ${ }_{1}$.

Palabras clave: Terapia anti-interleukina 5. Test de control del asma. Recuento de eosinófilos en sangre. Asma eosinofílica. FEV ${ }_{1}$.

Eosinophils play a pivotal role in the inflammatory processes of asthma and have been the target of new biologic treatments for eosinophilic asthma. Benralizumab is the monoclonal antibody that targets the $\alpha$ chain of the interleukin 5 (IL-5) receptor, and mepolizumab is the anti-IL-5 monoclonal antibody. We present the case of a patient with eosinophilic asthma and unsustained response to benralizumab after 3 years of therapy with mepolizumab.

A 42-year-old woman who had never smoked visited the clinic because of increasing dyspnea on January 22, 2016. She was treated with pranlukast $450 \mathrm{mg} / \mathrm{d}$ and fluticasone/ formoterol $125 \mu \mathrm{g} / 5 \mu \mathrm{g}$ inhaler (2 puffs per day). Because of unstable respiratory symptoms, she was occasionally given systemic corticosteroids. On February 27, 2016, the patient was admitted to hospital by an experienced pulmonologist.

We confirmed the diagnosis of asthma using the Global Initiative for Asthma guidelines [1]. Forced expiratory volume in 1 second $\left(\mathrm{FEV}_{1}\right)$ was $74.1 \%$ of predicted, with an increase of $14.1 \%$ in $\mathrm{FEV}_{1}$ after salbutamol $180 \mu \mathrm{g}$ (inhaler). The patient was not allergic. The results of testing indicated a serum total $\mathrm{IgE}$ level of $94 \mathrm{IU} / \mathrm{mL}$ and negative results in specific $\operatorname{IgE}$ for common inhaled allergens including Dermatophagoides farinae and Dermatophagoides pteronyssinus. Her regimen was changed to budesonide/formoterol $160 \mu \mathrm{g} / 4.5 \mu \mathrm{g}$ (8 puffs per day) and montelukast $10 \mathrm{mg} / \mathrm{d}$. She stopped using systemic corticosteroids, and daily use of the inhaler was reduced to 6 puffs per day on April 15.

On June 10 , the peripheral blood eosinophil count was $228 / \mu \mathrm{L}$, and serum total $\mathrm{IgE}$ was $155 \mathrm{IU} / \mathrm{mL}$. $\mathrm{FEV}_{1}$ (\% predicted) was $75.00 \%$, and the score on the Asthma Control Test (ACT) was 13. The patient agreed to receive the first dose of mepolizumab (100 mg) (Figure). She had no history of poor adherence or comorbidities. On July 9, her blood eosinophil count decreased to $26 / \mu \mathrm{L}$, while $\mathrm{FEV}_{1}$ and the ACT score were $75.17 \%$ and 16 . On November 26, the blood eosinophil count, $\mathrm{FEV}_{1}$, and the ACT score were $20 / \mu \mathrm{L}, 76.76 \%$, and 25 , 
and daily use of the inhaler was reduced to 4 puffs per day. On May 11, 2019, $\mathrm{FEV}_{1}$ improved to $79.69 \%$. The fact that she had been administered mepolizumab monthly for 3 years indicated successful long-term management of her asthma. No adverse effects were observed.

Benralizumab can be administered at longer dosing intervals than mepolizumab [2]. Therefore, on May 11, 2019, the patient started benralizumab $30 \mathrm{mg}$ every 4 weeks for the first 3 doses followed by a fixed-dose administration every 8 weeks. She continued to use her inhaler. On July 6 , the blood eosinophil count became undetectable. On August 31, she received the fourth dose. Although the blood eosinophil count remained undetectable, she complained of asthma symptoms (the ACT score fell to 21). Physical examination revealed slight wheezing during deep breathing. Adherence to the medication and inhaler technique were deemed adequate. The laboratory data did not reveal respiratory infection. The patient rejected systemic corticosteroids and was given aminophylline. On October 26 and December 21, the blood eosinophil count increased to $335 / \mu \mathrm{L}$ and $413 / \mu \mathrm{L}$, respectively, and the $\mathrm{FEV}_{1}$ and $\mathrm{ACT}$ score fell to $70.97 \%$ and $68.01 \%$ and
18 and 17. She received aminophylline on both days. On December 21, 2019, she refused to continue benralizumab and instead agreed to receive mepolizumab again every 4 weeks. On January 18, 2020, the blood eosinophil count, $\mathrm{FEV}_{1}$, and ACT score were $281 / \mu \mathrm{L}, 71.93 \%$, and 20 , and her asthma was gradually controlled. On August 29, 2020, the blood eosinophil count decreased to $30 / \mu \mathrm{L}$, and the $\mathrm{FEV}_{1}$ and ACT score increased to $79.53 \%$ and 25 .

The present case of eosinophilic asthma was uncommon. Despite responding to mepolizumab, the patient did not respond to benralizumab. We previously reported that eosinophilic asthma responded to benralizumab after failure to respond to mepolizumab [3], according to the same 3 efficacy endpoints. Blood eosinophil count has been approved as a biomarker for predicting the efficacy of anti-IL-5 therapy in patients with eosinophilic asthma [4] and was therefore main criterion. Based on the guidelines of the UK National Institute for Health and Care Excellence [5], we selected spirometry and lung function as the first 2 parameters to be monitored when determining the response to asthma treatment. As the third, we selected the ACT score [3].

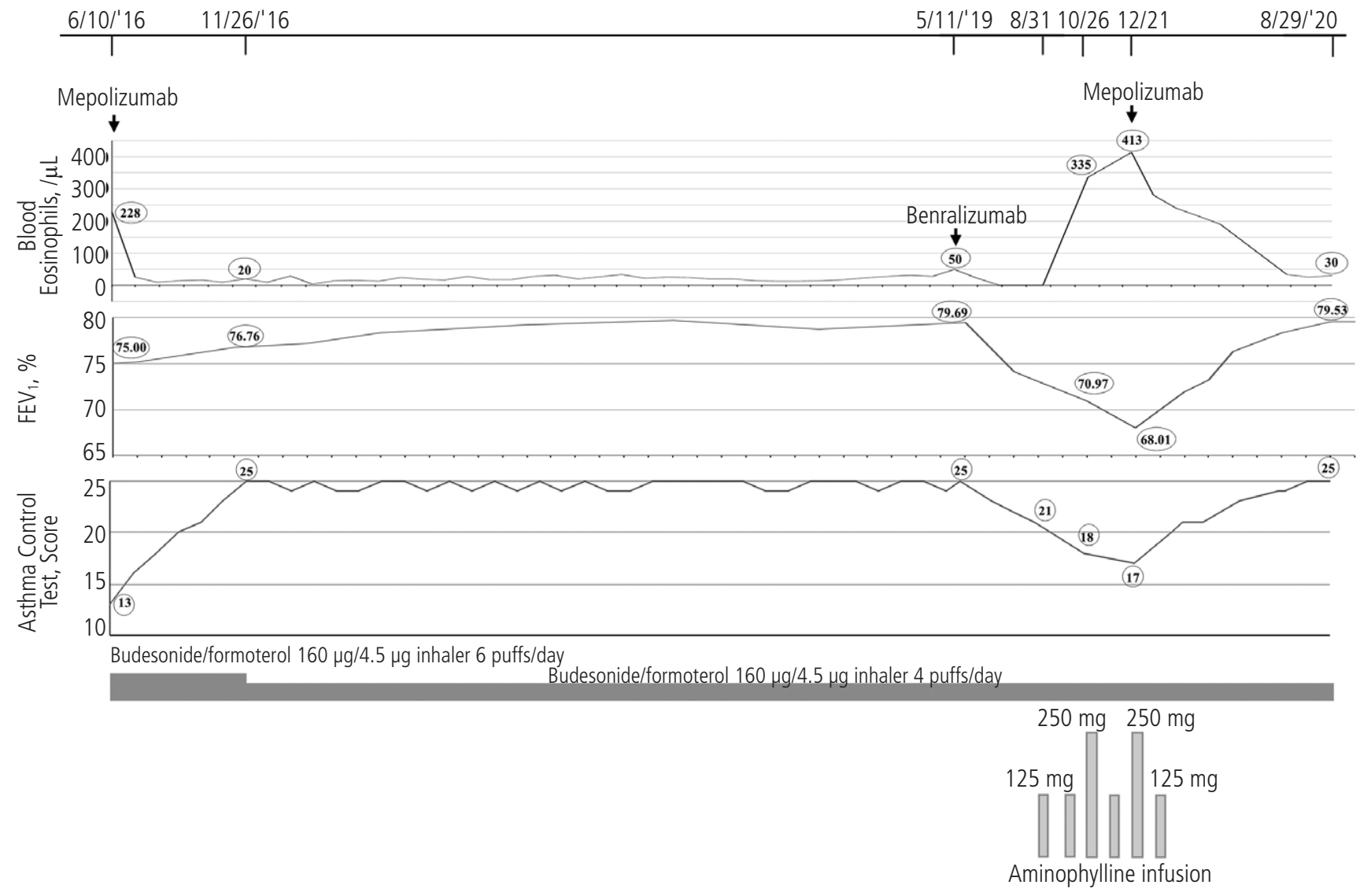

Figure. Clinical course of a patient diagnosed with eosinophilic asthma. After initiation of monthly mepolizumab on June 10, 2016 (peripheral blood eosinophil count, 228/uL; FEV $\%$ predicted, 75.00; and ACT score, 13), the patient's condition remained controlled for 3 years. On May 11, 2019 (eosinophil count, 50/ $\mu \mathrm{L} ; \mathrm{FEV}_{1}, 79.69 \%$; and ACT score, 25), she received benralizumab. Although the blood eosinophil count became undetectable, the pulmonary symptoms worsened (FEV1 and the ACT score dropped to $68.01 \%$ and 17). In parallel, the blood eosinophil count increased to $413 / \mu \mathrm{L}$, indicating an unsustained response to benralizumab. On December 21, 2019, the patient restarted monthly mepolizumab, and her asthma was gradually controlled. On August 29, 2020, the blood eosinophil count decreased to 30/ $\mu \mathrm{L}$, and the FEV 1 and the ACT score increased to $79.53 \%$ and 25. 
The first administration of mepolizumab was followed by a rapid reduction in blood eosinophil count, as reported elsewhere [3]. Reinitiating mepolizumab slowed this reduction. Recent data show secondary loss of response to mepolizumab in 2 patients with eosinophilic asthma after 2 years of treatment [6], in contrast with the present case.

Assessing the efficacy of benralizumab after 5 doses is difficult. The patient refused to continue with the drug and restarted mepolizumab instead. Our findings have 2 potential explanations. First, the BORA phase III extension trial showed that antidrug antibodies to benralizumab were developed by $10 \%$ of patients who received therapy every 4 weeks and in $12 \%$ who were treated every 8 weeks, with no effect on drug efficacy [7]. Since measurement of antidrug antibody to benralizumab is not available in our laboratory, no clear values could be reported. However, benralizumab has been shown to fully deplete blood eosinophils [8], as we observed. In addition, a sudden rise in the blood eosinophil count with treatment might be used as a biomarker of the development of antibody. Second, it is known that IL-5 is produced not only by CD4+ lymphocytes, but also by type 2 innate lymphoid cells in the airways [9]. Local eosinophilopoiesis may be the predominant process, and after 3 years of therapy with mepolizumab, benralizumab may not have achieved relevant blockade of eosinophilopoiesis [10].

In conclusion, to our knowledge, this is the first case of eosinophilic asthma that responded to mepolizumab, but not to benralizumab. Therefore, based on our previous report of a case where the patient responded to benralizumab after failure to respond to mepolizumab [3], full characterization of eosinophilic asthma is highly recommended for identification of responders to new biologic treatments.

\section{Acknowledgments}

The authors thank Junya Maehata, BSc, for assistance in assembling the figure.

\section{Funding}

The authors declare that no funding was received for the present study.

\section{Conflicts of Interest}

The authors declare that they have no conflicts of interest.
4. Yancey SW, Keene ON, Albers FC, Bleecker ER, Pavord I. Biomarkers for severe eosinophilic asthma. J Allergy Clin Immunol. 2017;140:1509-18.

5. Thorley J. NICE issues draft guideline for asthma diagnosis. Lancet Respir Med. 2015:3:184.

6. Cormier M, Chaboillez S, Lemiere C. Secondary loss of response to mepolizumab in severe eosinophilic asthma. J Allergy Clin Immunol Pract. 2020;8:736-8.

7. Busse WW, Bleecker ER, FitzGerald JM, Ferguson GT, Barker P, Sproule $S$, et al. Long-term safety and efficacy of benralizumab in patients with severe, uncontrolled asthma: 1-year results from the BORA phase 3 extension trial. Lancet Respir Med. 2019;7:46-59.

8. Kolbeck R, Kozhich A, Koike M, Mackay CR, Molfino NA, Coyle AJ, et al. MEDI-563, a humanized anti-IL-5 receptor alpha mAb with enhanced antibody-dependent cell-mediated cytotoxicity function. J Allergy Clin Immunol. 2010;125:134453.e2.

9. Smith SG, Chen R, Kjarsgaard M, Huang C, Oliveria JP, O'Byrne $P M$, et al. Increased numbers of activated group 2 innate lymphoid cells in the airways of patients with severe asthma and persistent airway eosinophilia. J Allergy Clin Immunol. 2016; 137:75-86.e8.

10. Sehmi R, Smith SG, Kjarsgaard M, Radford K, Boulet LP, Lemiere $C$, et al. Role of local eosinophilopoietic processes in the development of airway eosinophilia in prednisonedependent severe asthma. Clin Exp Allergy. 2016;46:793802.

- Manuscript received September 10, 2020; accepted for publication October 26, 2020.

Motohiro Kurosawa

Department of Allergy and Respiratory Medicine, Sutoh Hospital, 3532-5 Annaka, Annaka, Gunma 379-0116, Japan

E-mail: motohiro@kl.wind.ne.jp

\section{References}

1. Global Initiative for Asthma (GINA). Global strategy for asthma management and prevention. http//www.ginasthma.org/ local/uploads/files/GINA_Report_2015. Accessed February 14, 2016.

2. Davila Gonzalez I, Moreno Benitez F, Quirce S. Benralizumab: a new approach for the treatment of severe eosinophilic asthma. J Investig Allergol Clin Immunol. 2019;29:84-93

3. Kurosawa M, Sutoh E. Severe uncontrolled eosinophilic asthma, which responded to benralizumab after failure to respond to mepolizumab. Ann Allergy Asthma Immunol. 2019;122:431-3. 